\title{
Functional Assessment of Subacute or Chronic Low Back Pain by Subjective and Objective Measures
}

\author{
Ana Martínez-González¹, Javier Moreno-Díaz², Isabel Villarreal-Salcedo³, Eva M. Gómez-Trullén $n^{4}$ \\ Ana C. Royo-Sánchez ${ }^{5}$ and Jose J. Marín-Zurdo ${ }^{5}$
}

${ }^{1}$ Physical Medicine and Rehabilitation Service, Hospital of Barbastro, Huesca; ${ }^{2}$ Internal Medicine Service, University Hospital Miguel Servet, Zaragoza; ${ }^{3}$ Physical Medicine and Rehabilitation Service, University Clinical Hospital Lozano Blesa, Zaragoza; ${ }^{4}$ Department of Nursing and Physiatry, Faculty of Health and Sports Sciences, University of Zaragoza, Zaragoza; ${ }^{5}$ Engineering, University School, University of Zaragoza, Zaragoza. Spain

\begin{abstract}
Due to its high incidence, low back pain is a major problem from a social, health, and labor perspective. It is considered one of the most common causes of medical consultations in primary care, and one of the main reasons for temporary disability. A correct diagnostic approach and adequate therapeutic management will allow for better control of the clinical condition and its evolution. To do this, there are functional assessment techniques, both objective and subjective, which will provide fundamental information to perform appropriate management of the pathology, as well as to assess the effectiveness of the treatment. Within the subjective techniques, the Oswestry disability index is the most widely questionnaire used in hospitals, while the Roland Morris scale is used mainly in primary care. The results provided by the isokinetic and isoinertial techniques assess the functional capacity of the lumbar spine in an easy and convenient way for the patient. The main objective of this study is to present different subjective questionnaires and objective techniques to make a correct valuation of lumbar pain, improving access to adequate treatment and reducing work time.
\end{abstract}

Key words: Etiology. Functional assessment. Low back pain. Lumbar pain. Objective measures. Subjective measures.

\section{Introduction}

Lumbar pain is considered the most common reason for medical consultations, both in primary care and in specialized consultation ${ }^{1-3}$, and it affects $25-29 \%$ of the world population. However, the exact prevalence in Mexico is unknown. From the world figures, it is estimated that, in Mexico, it affects $28,000,000$ people, which means that it is the reason for $12-13 \%$ of medical consultations ${ }^{4,5}$. It is considered the main cause of limited activity in people younger than 45 years, and the most prevalent musculoskeletal pathology in people over 65 years of age $^{6}$, the most affected age group being between 30 and 60 years ${ }^{2,3}$. By gender, the prevalence of subacute and chronic lumbar pain is higher in women than in $\operatorname{men}^{7,8}$.

Most low back pain is self-correcting, but in $15-20 \%$ of cases, it becomes a chronic lumbar back pain ${ }^{9}$. This has caused back pain to be one of the primary causes of time off work and disability in industrialized countries, with the consequent economic expense secondary to the loss of productivity, compensation, and health care ${ }^{10}$.

The main objective of this study is to present different subjective questionnaires and objective techniques to

\section{Correspondence:}

Ana Martínez-González

E-mail: anamart15@ hotmail.com
Available online: $30-05-2018$

Date of reception: 27-11-2017

Date of acceptance: 07-02-2018

DOI: 10.24875/RMU.M18000009
Medicina Universitaria. 2018;20(1):46-54 www.medicinauniversitaria.org

列 CC BY-NC-ND license (http://creativecommons.org/licenses/by-nc-nd/4.0/). 
make a correct evaluation of lumbar pain, improving access to the adequate treatment and reducing time off work.

\section{Methodology}

A review of the etiology and lumbar pain assessment techniques has been carried out in indexed and non-indexed journals. In our search of articles, the following databases were used: PubMed, ScIELO, PeDRo, and Academic Google. The keywords used were: "low back pain," "etiology," "functional assessment," "objective techniques," and "subjective techniques."

Articles were selected according to the title, date of publication, summary, and later, full text. To evaluate the quality of the articles, the guidelines were used according to type and epidemiological design.

\section{Etiology of low back pain}

The studies of Manek and MacGregor ${ }^{11}$ and Humbría-Mendiola et al. ${ }^{12}$ reported that in approximately 80 $85 \%$ of instances of low back pain, there is no specific lesion that justifies the clinical attention. This diagnostic limitation supposes a chronification of the symptoms in up to $10-15 \%$ of the cases, evolving to disability and consuming up to $75 \%$ of the total resources dedicated to lumbar pathology ${ }^{1,2}$. Different risk factors could interact with each other, contributing to the development and maintenance of pain. The knowledge of the risk factors for the development of low back pain can be useful for the development of preventive strategies.

In relation to the body mass index, there is a clear relationship between weight and back pain. Therefore, it is necessary to avoid excessive weight gain ${ }^{13,14}$. Regarding psychosocial factors, when compared to the general population, patients suffering from low back pain have been shown to have a higher prevalence of depression, anxiety, substance abuse, and somatization. Thus, depression is present in $40-65 \%$ of those affected by low back pain, while this percentage is reduced to $5-17 \%$ in the general population ${ }^{15,16}$. Furthermore, psychological disorders have been identified as a cause of the chronification of lumbar pain, since they act as risk factors that can independently increase the probability of hospitalization for back pain ${ }^{15}$.

In relation to work activity, it has been observed that the main cause of non-specific low back pain is usually due to over-efforts repeated over time, and not due to direct trauma. There is reasonable evidence that there are factors related to work activity that is associated with back pain as well ${ }^{17}$. In the National Institute for Occupational Safety and Health the experts came to the conclusion that the main movements generating back pain are: anterior flexion, bending with torsion, hard physical work with repetition, work in an environment with vibrations, and work in static postures ${ }^{18}$.

In addition, physical inactivity predisposes patients to a worse evolution of low back pain and a tendency to chronify it ${ }^{14}$. For Kovacs, this physical inactivity will result in a loss of coordination, muscular power, and finally atrophy ${ }^{19}$. This situation, along with the consolidation of fear and avoidance behaviors, will lead to catastrophic thoughts and passive attitudes, projecting responsibility for the ailment and its consequences onto third parties ${ }^{16}$.

\section{Functional evaluation of lumbar pain}

When performing the assessment of a lumbar pathology, there is sometimes a discrepancy between the clinical and the imaging tests. In addition, psychological, social, and work factors influence the chronification of the process, increasing the perception of pain and therefore generating a negative effect on the evolution of the process. To perform a correct assessment of lumbar pain, in 2001 the World Health Organization proposed the model of disability still in use today, which is represented in the International Classification of Functioning, Disability, and Health, based on a biopsychosocial model ${ }^{6}$.

This new classification calls for an analysis of lumbar pathology from an objective point of view, also taking into account the subjective data displayed by the patient. This concept leads to the use of tests that allow a broader study of low back pain and its impact on the daily activities of patients. The scales and assessment techniques most used in daily practice are described below.

\section{Subjective assessment}

These scales provide information on the intensity and impact of pain in the activities of daily life. There are one-dimensional and multidimensional methods to analyze the intensity of pain. The degree of disability is assessed through specific questionnaires: the Oswestry Low Back Disability Questionnaire, Roland Morris Disability Questionnaire (RMDQ), Waddell and Main Disability Index, or Quebec Back Pain Disability Scale (QBPDS). The Oswestry and Ronald-Morris questionnaires are the most used and recommended worldwide $20-22$. 


\section{Pain InTENSITY}

The options for pain measurement tools are vast, and include both one-dimensional and multidimensional methods:

- One-dimensional methods: treat pain as a single or simple dimension, and only assess its intensity. They are easy to use and understand. Among them, these stand out:

- "Simple descriptive pain intensity scale" or verbal assessment: it was described by Keele in $1948^{23}$. It represents the most basic approach to measuring pain and is generally useful for the researcher due to its ease of application. Each of the terms (absence of pain $/ \mathrm{mild} /$ moderate/intense) are assigned a score for the statistical treatment of the results and the practical assessment of the same. Although it is used in numerous clinical trials on pain, it is a non-specific scale that is not very sensitive and not always reproducible ${ }^{24}$.

- "Numeric pain rating scale:" introduced by Downie in 1978, it is one of the most commonly used ${ }^{25}$. The patient must assign their pain to a numerical value between two extreme points (0-10). Although the subject is asked to use numerical values to indicate the level of their pain, the use of keywords, as well as previous instructions, are necessary for the correct use of this scale. With this type of scale, pain is considered a simple one-dimensional concept and is measured only according to its intensity. It is useful as a measuring instrument to assess the response to a selected treatment ${ }^{24,26}$.

- "Visual analog scale (VAS pain):" this scale has its origin in psychology, where it was used to assess the mood of the patient. It soon began to be used as a scale for pain assessment, although it was not until 1976 that Huskisson and Scott thought about applying it more broadly to assess pain ${ }^{27,28}$.

It consists of a line $10 \mathrm{~cm}$ (3.94 in) long that represents the intensity of the pain. Only at the extremes are descriptions, "no pain" and "the worst pain imaginable." The patient is not asked to describe his pain with specific words but is free to indicate on this line the intensity of his painful sensation in relation to the two extremes of the same. The score is measured from zero to the patient's mark and can be measured in centimeters or millimeters ${ }^{29}$.

The VAS is a simple, reliable, sensitive, and reproducible instrument, being useful to reevaluate pain in the same patient on different occasions. Its validity for the measurement of experimental pain has been demonstrated in numerous studies, and its reliability has also been recently evaluated as satisfactory ${ }^{28,30,31}$. It is the measurement method most frequently used in many pain assessment centers since it is sensitive to changes.

- Multidimensional methods: these provide information on the qualitative and quantitative aspects of pain. Among the most used is the following questionnaire.

- "The McGill Pain Questionnaire:" the objective is to provide an assessment of pain from a triple perspective:

1. Sensory: description of pain in temporal-spatial terms.

2. Affective-motivational: description of pain in terms of tension, fear and neurovegetative aspects.

3. Evaluative: pain described in terms of general assessment.

Specifically, the instrument consists of 78 adjectives distributed in 20 groups, each group including 2-6 adjectives that qualify the painful experience. Each of the descriptive terms is assigned a number or range that allows you to obtain a score according to the chosen words. With this, you get the "Pain Rating Index." This score reflects the way in which the patient qualifies his or her own painful experience, allowing the researcher to assess the influence of emotional and sensory factors involved ${ }^{32}$.

\section{Assessment of disability}

\section{OsWestRY}

It is a simple and practical questionnaire, developed by Fairbank in 1980 and adapted to Spanish in 1995 by Flórez García ${ }^{33,34}$. The Oswestry questionnaire was widely disseminated in 1981 after the meeting of the International Society for The Study of the Lumbar Spine in Paris ${ }^{35}$. The Oswestry Low Back Pain Scale is a self-applied questionnaire, specific to low back pain, which measures limitations in daily activities $^{35}$.

It consists of 10 questions with 6 response possibilities each, which are mutually exclusive. The first question refers to the intensity of the pain, specifying in the different options the response to taking analgesics. The remaining items include basic activities of daily living (ADL) that can be affected by pain (personal care, lifting weight, walking, sitting, standing, sleeping, sexual activity, social life, and traveling) ${ }^{20}$. 
Version 2.0 is a modification made by the Medical Research Council Group, in which you specify that you should mark the option that best describes your situation on the same day that the questionnaire is complet$\mathrm{ed}^{20}$. The original version does not clarify this aspect, but for the development of this study, patients were asked to answer in relation to how they were at the time of self-completion.

The results are classified as follows:

- $0-20 \%$ minimal disability

- $20-40 \%$ moderate disability

- $40-60 \%$ severe disability

- $60-80 \%$ very severe disability

- $>80 \%$ it is necessary to assess non-organic signs that can alter the perception of pain.

Oswestry's low back pain scale is one of the most used scales in clinical trials with a control group, in evaluation protocols ${ }^{20}$. Since its appearance more than 20 years ago, it has been the subject of numerous studies, and it has been concluded that high Oswestry values have a predictive value with the chronification of pain, duration of sick leave, and the result of conservative or surgical treatments. Fairbank and Torenbeek recommend the use of this questionnaire in those patients who have a moderate-intense disability. It is one of the most used scales in European rehabilitation centers and has served as a reference to determine the validity of other scales ${ }^{33,36}$.

\section{ROLAND-MORRIS}

Adapted to the Spanish population by Kovacs ${ }^{37}$, the RMDQ assesses physical and psychological disability due to lumbar pain. Kovacs recommends its use especially in primary care, where we find patients who have a low functional limitation ${ }^{38}$.

The RMDQ is a self-administered instrument consisting of 24 items, with two response options (yes/no). Results range from 0 , the absence of disability due to low back pain, to 24 , maximum possible disability ${ }^{21}$. A disability below 4 points is very slight. A variation in the score only has clinical relevance if it is of two or more points, although the optimal variation is between 3 and 4.

\section{WADDELL AND MAIN DISABILITY INDEX}

Radiographs of patients over 50 years old show degenerative changes in $87 \%$ of cases $^{19}$. Authors such as Nachemson or Flórez agree in their conclusions that although anatomical or degenerative changes are present in radiological images, they are not necessarily the origin of the pain ${ }^{39,40}$. It is because of this that sometimes, we see a disagreement between the clinic and the imaging tests. In these situations, we must take into account the existence of non-organic signs such as the presence of inappropriate behavior facing the disease and its relationship with functional activity.

In such cases, there is a need for further investigation of the patient through the Waddell and main disability index ${ }^{39,40}$. It consists of nine items, which assess whether the patient has reduced the basic ADLs if they need help to perform them or have an avoidance attitude toward them.

The signs of a lack of organicity in the Waddell Index are: superficial and non-anatomical pain, hyper-reaction to the examination, a decrease or loss of sensibility in muscle areas, no pain with the Lasègue test performed with the patient distracted, pain in a simulated rotation, and pain to axial compression. Patients who exhibit some of these signs take 4 times more to return to work and consume many more diagnostic and therapeutic resources ${ }^{41}$.

\section{QBPDS}

The QBPDS is a self-administered questionnaire developed by Kopec in 1995 and consists of 20 items, which have the objective of measuring the degree of disability that causes back pain in the performance of ADL. The score of each item ranges from 0 to 5 , and the maximum score is 100 . This scale can be used as a way to measure results after treatment or control of clinical evolution. It is considered that the minimum variation of improvement is 15 points ${ }^{18,42,43}$.

\section{Objective assessment}

Given the diagnostic and therapeutic complexity, the use of objective measures is essential to analyze how lumbar pain affects the patient's activities.

When performing a proper assessment, it is recommended to study joint balance, muscle strength, and muscle activation separately.

\section{AsSESSMENT TECHNIQUES FOR JOINT BALANCE}

The measurement of joint balance will be an objective marker of the level of improvement in a patient with low back pain.

Furthermore, measuring the range of lumbar mobility is an important indicator of the progress and effectiveness 
of a treatment $t^{44}$. There are different techniques to measure the mobility of the spinal column, but there is no clear evidence to recommend one method over another ${ }^{45}$. The measuring instruments currently used (in recent years) are the following:

\section{Inclinometers}

Inclinometers are measuring devices that provide the angle of inclination of the lumbar column with respect to the vertical ${ }^{44}$. The double inclinometer is recommended for the assessment of the range of lumbar mobility, which will provide more specific information about the movement performed by the lumbar spine. This technique has improved in recent years; since electronic inclinometers have been developed, they provide information on both the static and dynamic column.

\section{Goniometers/electrogoniometers}

These are instruments for measuring angles between two segments. Their simplicity and ease of use have allowed their use in clinical studies and daily practice. However, the use of manual goniometers in the assessment of joint ranges in the lumbar spine is rare, due to the difficulty in aligning the two branches of the goniometer when assessing flexion and extension. Therefore, visual estimation or inclinometers are frequently used.

Despite their simplicity, they are being replaced by photogrammetry techniques, which provide much more information ${ }^{44}$.

\section{Photogrammetry and electromagnetic systems}

Photogrammetry allows us to obtain several simultaneous images of the patient from different angles. The use of this technique is very widespread in the global assessment of combined movements of different joints, as a complement to movement analysis techniques ${ }^{46}$. The kinematic analysis of the image allows us to start from a real movement and study the different parameters of the movement being carried out ${ }^{47}$.

The "virtual models" that seem to imitate the movements and gestures of human beings were developed with Motion Capture software (MoCap). Currently, different MoCap technologies and systems are available, but perhaps the most widely used are based on optical methods. These use reflective spherical markers and infrared-light cameras capable of collecting the reflection of the markers. These portable motion sensors emit a magnetic field, and software is used to capture and analyze the movements later.

The information provided by the sensors in combination with the 3D animation software, transfers and reproduces the movements to a biomechanical model. This allows accurate analysis of the captured movements. In each of the joints being analyzed, you can assess the maximum mobility as well as the speed, angular acceleration of the movement, and the restriction of it with respect to normality ${ }^{48}$.

Within motion capture systems, the Vicon MX system is the most advanced available optical system. The main components of a Vicon ${ }^{\circledR}$ system are the cameras, the control hardware module, the software (to analyze and present the data), and the equipment to run the software.

Another of the most used analysis systems is the inertial system ViMove ${ }^{\circledR}$. Its validity has been investigated and confirmed in a study conducted by Mjøsund $\mathrm{HL}$, in comparison with the reference measurements of the Vicon ${ }^{\circledR}$ motion capture system. There have been differences of $<2^{\circ}$ between the data collected by each of the systems, proving the validity of the ViMove ${ }^{\circledR}$ system for the study of movement. This system is capable of measuring the three dimensions of lumbosacral spine movements for $24 \mathrm{~h}$, capturing data on the patient's record and perception of pain, in addition to providing biofeedback ${ }^{49}$.

It was Cuesta-Vargas Al who determined that these tests have a validity range of $0.657-0.998$ and reliability of $0.84-0.97^{50}$. These data have favored the use of inertial sensors in basic and clinical research ${ }^{51}$.

\section{Assessment teCHNIQUeS fOR MUSCle balance}

Since the beginning of medical history, an attempt has been made to define the functional capacity of a muscle group, to know the strength, power, and work that it executes ${ }^{50,51}$. To this end, various means have been used, ranging from manual exploration techniques to stimulation through electrodiagnosis, spring balance methods, grasping systems, weightlifting, etc., all of them aimed at defining and classifying the strength and power developed by the different muscle groups ${ }^{51,52}$.

Since 1897, there have been different attempts to create an instrument for measuring muscle strength. The Daniels Scale proposes an ordinal system (categories) of muscular valuation in $5^{\circ 51}$. This scale is the most widely used and currently disseminated in clinical 
practice. Despite efforts to find an objective technique, these functional assessment tests have a subjective component which defines them ${ }^{53}$.

The attempt to find a purely objective method is one of the bases for the appearance of the Isokinetic method. Over the years, and thanks to advances in research, it has been seen that there is a direct relationship between low back pain, muscle weakness, and a loss of resistance ${ }^{12}$. The assessment of muscle strength during the performance of isometric, isokinetic or isotonic efforts, is made through dynamometry, obtaining mechanical variables such as torque or moment of force, the speed of movement, or the displacement of the trunk ${ }^{52}$.

Following the Mc-Gorry classification, the dynamometers can be divided into two systems: passive and active. The passive system uses mechanical, magnetic, hydraulic or electric brakes to dissipate the forces. It can be used in the modalities of concentric, isotonic, or isometric isokinetic exercises. Active dynamometric systems dissipate the force produced by a person or produce force to work on the person. In addition to possessing the faculties of a passive system, they can perform eccentric and passive isokinetic modality exercises $^{54}$. Huesa considers dynamometry an important clinical, functional test at the time of assessing this pathology since it allows us to objectify the deficit and also to evaluate the patient's collaboration ${ }^{54}$. These techniques have been widely studied, and their validity and reliability are shown in the bibliography ${ }^{52,55,56}$. The most used systems are:

\section{Isokinetic techniques}

Isokinetic movement is defined by maintaining an angular velocity of constant movement during the entire articular course. This speed will be programmed, and the resistance will adapt to the joint biomechanics. As well as isotonically, it can be done concentrically and eccentrically.

In an isokinetic exercise, the resistance is adapted to the opposite external force, so that the muscle retains the maximum performance in the entire range of movement. Isokinetic exercises are performed at a predetermined speed, with a variable resistance, which accommodates the individual along the arc of movement.

Isokinetic dynamometry is an objective way to measure the dynamic muscle strength performed, both in an analytical movement on an articular axis (isokinetic in open chain) and as a complex movement involving several joints (isokinetic in the closed chain). It allows the objectification of the deficits of mobility and strength of the muscles of the spine, as well as its alteration affecting the lumbar function ${ }^{55}$.

Dvir $Z$ concludes that in chronic low back pain, there is a loss of extensor power from the spine, and it has, therefore, been a parameter used to qualify the intensity of the described deficits ${ }^{55,57}$.

This technique is one of the most used as a measure of functional assessment and sports training ${ }^{54,57}$. However, we must take its high cost into account. In addition, high user experience and long test time are necessary $y^{58}$.

\section{Isometric techniques}

In isometric muscle contraction, the distance between the origin and the muscle insertion remains constant. Therefore, there is no movement as a result of the contraction: the speed of movement is zero and the muscular work is also zero ${ }^{57}$.

In clinical practice, these isometric dynamometry tests stand out: the Biering-Sorensen Test, the Ito Test, and the Side-Bridge Test. These tests are characterized by their ease of implementation, and the low cost involved since the main measuring instrument is their own body. However, they have numerous deficiencies. Since they are an open kinetic chain exercise, the movement will be highly dependent on the strength of each patient, so there will be interindividual variations in the results depending on the patient's gender and the body mass of their arms and trunk ${ }^{58-60}$.

A study conducted by Harding et al. assessed the effectiveness of the portable dynamometer system or Hand Held Dynamometry (HHD). This system is an attractive alternative to isokinetic dynamometry. It is simple, fast, and economical, therefore highly practical for use in the clinical environment. The validity of this technique has been confirmed in the measurements of the upper and low limb strength ${ }^{61}$.

The validity of the strength measurement of the extensor musculature has recently been demonstrated by the use of the HHD belt system through external fixation $^{58}$. It has the advantages of low cost, the data obtained being simple to interpret, and easily reproducible techniques. However, there is uncertain evidence of a connection between isometric muscle capacity and dynamic function ${ }^{44}$.

\section{Isotonic techniques}

In the isotonic movement, there is a contraction against a constant load or mass. As a consequence of 
this contraction modality, there is a change in the distance between the origin and the insertion of the muscle, that is, a movement.

Isotonic contractions are the most common in most physical activities, sports, and daily activities. They are classified as:

- Concentric: those in which a muscle develops enough tension to overcome resistance. Thus, the muscle shortens and overcomes that resistance. Most isotonic techniques are concentric valuations.

- Excentric: muscle elongation occurs when resistance is greater than the tension exerted by a given muscle. Thus, the muscle develops tension by increasing its length ${ }^{44}$.

The technique of isotonic valuation is usually used together with surface electromyographic (sEMG) studies.

\section{Isoinercial techniques}

An isoinertial contraction is defined as that during which there is a constant resistance, against which the movement (of inertia) is carried out. The variables analyzed with this technique will be those derived from torque (work and power) and speed (acceleration) ${ }^{62}$.

During work activity or in daily life, the movements performed require dynamic contractions, with variable time speeds, of the trunk and extremities. It is the isoinertial techniques that most closely approach the evaluation of these movements. Among its disadvantages are the high cost and their limited availability ${ }^{44}$.

\section{Dynamometric platforms}

During the analysis of a movement, the dynamometric platforms allow the recording of the reaction forces, which are exerted by an individual on the ground. This way we can obtain its kinetic parameters. When performing a low back pain assessment, they are the most important among the kinetic techniques, since they are often used in combination with other techniques, such as motion capture and/or EMG ${ }^{10}$.

\section{MUSCle ACtivation ASSESSMENT TECHNIQUES}

\section{Electromyography (EMG)}

sEMG allows the measurement of muscle activity using surface electrodes. These are placed on the skin adjacent to the muscular area to be evaluated, with a frequency band between 20 and $500 \mathrm{~Hz}$. From the electromyographic record, we try to obtain measurements of the sequence of muscular activation, static effort, and muscular strength ${ }^{44}$. For Geisser ${ }^{63}$, the reason for using EMG in the evaluation of low back pain is the apparent relationship between low back pain, contracture, and fatigue. One possible theory is that fatigue secondary to muscle inactivity and inhibition of muscle activation secondary to pain could directly influence the etiology of pain ${ }^{62}$.

It seems that the EMG test can distinguish between healthy and sick patients. However, there is no clear evidence that any electromyographic parameter (used in isolation) discriminates validly and reliably between patients with low back pain and asymptomatic subjects and during tasks of trunk flexion, extension, or rotation ${ }^{52}$

Their main limitations are the emission of low-resolution signals and presenting a susceptibility to the introduction of artifacts in the image. It also requires experience on the part of the professional who performs the test.

\section{Conclusion}

For the adequate assessment of the patient with low back pain, the combination of objective and subjective scales is necessary. Among the subjective techniques, the Oswestry disability scale is the most used questionnaire at the hospital level, while the Roland-Morris scale is the one most used in primary care.

In those cases where the clinical manifestations are not concordant with the imaging tests, the Waddell and Main Disability Index provide a diagnostic orientation. Due to this, it is important to perform objective techniques that allow an evolutionary monitoring of the pathology and its treatment.

The results provided by isokinetic and isoinertial techniques assess the functional capacity of the lumbar spine in a simple and comfortable way for the patient. EMG techniques used in isolation allow us to differentiate between healthy and affected subjects, but it is usually used together with other techniques to perform a global study of the patient.

Given that there is no unanimity on which assessment technique is the most specific, we believe it is necessary to continue carrying out a high-quality clinical studies on the efficacy and validity of different assessment techniques. 


\section{Ethical disclosures}

Protection of human and animal subjects. The authors declare that no experiments were performed on humans or animals for this study.

Confidentiality of data. The authors declare that no patient data appear in this article.

Right to privacy and informed consent. The authors declare that no patient data appear in this article.

\section{Funding}

The authors declare that they have not received external funding to develop the study.

\section{References}

1. Arana-Guajardo AC, Vega-Morales D, Galarza-Delgado DA, Garza-Elizondo MA. Abordaje si0111stemático de la lumbalgia. Med Univ. 2013; 15:188-192.

2. Hoy D, Bain C, Williams G, et al. A systematic review of the global prevalence of low back pain. Arthritis Rheum. 2012;64:2028-37.

3. Chou R, Deyo R, Friedly J, et al. Systemic pharmacologic therapies for low back pain: a systematic review for an American college of physicians clinical practice guideline. Ann Intern Med. 2017;166:480-92.

4. Guevara-López. U, Covarrubias-Gómez A, Elias-Dib J, Reyes-Sánchez A Rodriguez-Reyna TS. Parámetros de práctica para el manejo del dolor de espalda baja. Cir Cir. 2011;79:286-302.

5. Covarrubias-Gómez A. Lumbalgia: un problema de salud pública. Rev Mex Anestes. 2010;33:S106-9.

6. Miró J, Paredes S, Rull M, et al. Pain in older adults: a prevalence study in the Mediterranean region of Catalonia. Euro J Pain. 2007;11:83-92.

7. Esteban-Peña M, García RJ, Olalla JM, Llanos EV, de Miguel AG Cordero XF. Impact of the most frequent chronic health conditions on the quality of life among people aged $>15$ years in Madrid. Eur J Public Health. 2010;20:78-84.

8. Ge HY, Madeleine P, Arendt-Nielsen L. Sex differences in temporal characteristics of descending inhibitory control: an evaluation using repeated bilateral experimental induction of muscle pain. Pain. 2004; 110:72-8.

9. Mendiola AC, Sagredo JL, Ortiz AM. Impacto poblacional del dolor lumbar en España: resultados del estudio EPISER. Rev Esp Reumatol. 2002;29:494-8.

10. Peydro MF, López J, Cortés A, Garrido JD, Tortosa L. Análisis cinético y cinemático del gesto levantarse de una silla en pacientes con lumbalgias. Rehabilitación. 2011;45:99-105

11. Manek NJ, MacGregor AJ. Epidemiology of back disorders: prevalence, risk factors, and prognosis. Curr Opin Rheumatol. 2005;17:134-40.

12. Humbría-Mendiola A, Carmona L, Ortiz AM, Peña-Sagredo JM. Tratamiento de la lumbalgia inespecífica: ¿qué nos dice la literatura médica? Rev Esp Reumatol. 2002;29:494-8.

13. Daentzer $D$, Hohls $T$, Noll $C$. Has overweight any influence on the effectiveness of conservative treatment in patients with low back pain? Eur Spine J. 2015;24:467-73.

14. Wasser JG, Vasilopoulos T, Zdziarski LA, Vincent HK. Exercise benefits for chronic low back pain in overweight and obese individuals. PM $R$ 2017:9:181-92.

15. Reme SE, Lie SA, Eriksen HR. Are 2 questions enough to screen for depression and anxiety in patients with chronic low back pain? Spine (Phila Pa 1976). 2014;39:E455-62.

16. Pincus T, Burton AK, Vogel S, Field AP. A systematic review of psychological factors as predictors of chronicity/disability in prospective cohorts of low back pain. Spine (Phila Pa 1976). 2002;27:E109-20.

17. Guisado JP. Contribución al estudio de la lumbalgia inespecífica. Rev Cubana Ortop Traumatol. 2006;20:2.

18. Kim GM, Yi CH, Cynn HS. Factors influencing disability due to low back pain using the Oswestry disability questionnaire and the Quebec back pain disability scale. Physiother Res Int. 2015;20:16-21.

19. Kovacs FM, Arana E. Degenerative disease of the lumbar spine. Radiologia. 2016;58 Suppl 1:26-34.
20. Alcántara-Bumbiedro S, Flórez-García MT, Echávarri-Pérez C, García-Pérez F. Escala de incapacidad por dolor lumbar de Oswestry. Rehabilitacion. 2006;40:3.

21. Guic E, Galdames S, Rebolledo P. Adaptación cultural y validación de la versión chilena del cuestionario de discapacidad roland-morris. Rev Med Chile. 2014;142:716-22.

22. Roland M, Fairbank J. The roland-morris disability questionnaire and the oswestry disability questionnaire. Spine (Phila Pa 1976). 2000;25:3115-24.

23. Keele KD. The pain chart. Lancet. 1948;2:6-8.

24. Serrano-Atero MS, Caballero J, Cañas A, García-Saura PL, Serrano-Álvarez C, Prieto J. Valoración del dolor (I). Rev Soc Esp Dolor. 2002;9:94-108.

25. Downie WW, Leatham PA, Rhind VM, et al. Studies with pain rating scales. Ann Rheum Dis. 1978;37:378-81.

26. Díez-Burón F, Marcos-Vidal J, Baticón-Escudero PM, Montes-Armenteros A, Bermejo-López JC, Merino-Garcia M. Concordancia entre la escala verbal numérica y la escala visual analógica en el seguimiento del dolor agudo postoperatorio. Rev Esp Anestesiol Reanim. 2011;58:279-82.

27. Huskisson EC. Measurement of pain. Lancet. 1974;1:80.

28. Scott J, Huskisson EC. Graphic representation of pain. Pain. 1976; 2:175-84.

29. Poquet N, Lin CW, Heymans MW, et al. Back schools for acute and subacute non-specific low-back pain. Cochrane Database Syst Rev. 2016;4:CD008325

30. Fishbain DA, Gao J, Lewis JE, Zhang L. At completion of a multidisciplinary treatment program, are psychophysical variables associated with a VAS Improvement of $30 \%$ or more, a minimal clinically important difference, or an absolute VAS score improvement of $1.5 \mathrm{~cm}$ or more? Pain Med. 2016;4:781-9.

31. Bijur PE, Plata W, Gallagher EJ. Reliability of the visual analog scale for measurement of acute pain. Acad Emerg Med. 2001;8:1153-7.

32. Nava-Bringas TI, Roeniger-Desatnik A, Arellano-Hernández A, Cruz-Medina $E$. Adherencia al programa de ejercicios de estabilización lumbar en pacientes con dolor crónico de espalda baja. Cir Cir. 2016:84:384-91.

33. Fairbank JC, Pynsent PB. The oswestry disability index. Spine (Phila Pa 1976). 2000;25:2940-52.

34. Flórez-García M, García-Pérez MA, García-Pérez F, Armenteros-Pedreros J, Álvarez-Prado A, Martínez-Lorente MD. Adaptación transcultural a la población española de la escala de incapacidad por dolor lumbar de Oswestry. Rehabilitacion (Madrid). 1995;29:138-45.

35. Fairbank JC. Oswestry disability index. J Neurosurg Spine. 2014;20: 239-41.

36. Torenbeek M, Caulfield B, Garret M, Van Harten W. Current use of outcome measures for stroke and low back pain rehabilitation in five European countries: first results of across project. Int $\mathrm{J}$ Rehabil Res. 2001;24:95-101.

37. Kovacs FM, Llobera J, Gil Del Real MT, et al. Validation of the Spanish version of the roland-morris questionnaire. Spine (Phila Pa 1976). 2002;27:538-42.

38. Kovacs FM. El uso del cuestionario de Roland-Morris en los pacientes con lumbalgia asistidos en atención primaria. Semergen. 2005;31:331-5.

39. Nachemson A. Newest knowledge of low back pain. A criticallook. Clin Orthop Rel Res. 1992;279:8-20.

40. Flórez MT, García F, Valverde MD, Conejero JA. Correlaciones clínicoradiológicas en el dolor vertebral. Rehabilitacion (Madrid). 1992;26:258-68.

41. Miralles RC, Rull M. Valoración de los resultados del tratamiento del dolor lumbar y de las secuelas. Rev Soc Esp Dolor. 2001;8:131-9.

42. Kopec JA, Esdaile JM, Abrahamowicz M, et al. The quebec back pain disability scale. Measurement properties. Spine (Phila Pa 1976). 1995;20:341-52.

43. Speksnijder CM, Koppennal T, Knottnerus JA, Spigt M, Staal JB, Terwee CB. Measurement properties of the Quebec back pain disability scale in patients with nonspecific low back pain: a systematic review. Phys Ther. 2016;96:1816-31.

44. Peydro de Moya MF, Garrido D, López J. Valoración instrumental de la movilidad raquídea. In: Sánchez I, Ferrero A, Aguilar JJ, et al. editors. Manual SERMEF de Rehabilitación y Medicina Física. $6^{\text {th }}$ ed., Vol. 1. Panamericana; 2006. p. 95-7.

45. MacDermid JC, Arumugam V Vincent JI, Carroll KL. The reliability and validity of the computerized double inclinometer in measuring lumbar mobility. Open Orthop J. 2014;8:355-60.

46. Villa A, Gutierrez GE, Pérez JC. Consideraciones para el análisis de la marcha humana. Técnicas de videogrametría, electromiografía y dinamometría. Rev Ing Biomed. 2008;3:16-26.

47. Stewart TD, May RM. Basic biomechanics of human joints: hips, knees and the spine. Curr Orthopaed. 2006;20:23-31.

48. Hueso-Calvo R, Marín-Zurdo J. Valoración de una herramienta, para el estudio del movimiento, en la valoración del daño corporal. Trauma Fund Mapfre. 2011:22:219-25.

49. Mjøsund HL, Boyle E, Kjaer P, et al. Clinically acceptable agreement between the viMove wireless motion sensor system and the vicon motion capture system when measuring lumbar region inclination motion in the sagittal and coronal planes. BMC Musculoskelet Disord. 2017;18:124. 
50. Cuesta-Vargas Al, Galán-Mercant A, Williams JM. The use of inertial sensors system for human motion analysis. Phys Ther Rev. 2010; 15:462-73.

51. Al-Mulla MR, Sepulveda F, Colley M. A review of non-invasive techniques to detect and predict localised muscle fatigue. Sensors (Basel). 2011;11:3545-94.

52. Cruz-Medina E, León-Hernández SR, Arellano-Hernández A, Martínez-Gonzaga E, García-Guerrero E, Coronado-Zarco R. Evaluación isocinética y estado funcional en pacientes posoperados por hernia de disco lumbar. Cir Ciruj. 2008;76:373-80.

53. Peyer KE Morris M, Sellers WI. Subject-specific body segment paramete estimation using 3D photogrammetry with multiple cameras. Peer J. 2015;3:831.

54. Huesa-Jimenez F, García-Díaz J, Vargas-Montes J. Dinamometría isocinética. Rehabilitacion (Madrid). 2005;39:288-96.

55. Ridao N, Sánchez MD, Chaler J, Müller B. Aportación de la dinamometría isocinética de columna lumbar en una mutua laboral. Trauma Fund Mapfre. 2009;5:229-33.

56. Kim CR, Park DK, Lee ST, Ryu JS. Electromyographic changes in trunk muscles during graded lumbar stabilization exercises. M R. 2016;8:979-89.
57. Dvir Z, Keating JL. Trunk extension effort in patients with chronic low back dysfunction. Spine. 2003;28:685-92.

58. Harding AT, Weeks BK, Horan SA, Little A, Watson SL, Beck BR. Validity and test-retest reliability of a novel simple back extensor muscle strength test. SAGE Open Med. 2017;5:2050312116688842.

59. Juan-Recio C, Barbad-Murillo D, López-Valenciano A, Vera-García F. Test de campo para valorar la resistencia de los músculos del tronco. Apunts Educ Fís Deportes. 2014;117:59-68.

60. Demoulin C, Vanderthommen M, Duysens C, Crielaard JM. Spinal muscle evaluation using the Sorensen test: a critical appraisal of the literature. Joint Bone Spine. 2006;73:43-50.

61. Bohannon RW, Kindig J, Sabo G, Duni AE, Cram P. Isometric knee extension force measured using a handheld dynamometer with and without belt-stabilization. Physiother Theory Pract. 2012;28:562-8.

62. Ramos-Cristóbal JA, Arsuaga-Urriza L. Revisión de la evaluación isoinercial de columna lumbar. Rehabilitación. 2005;39:106-8.

63. Geisser ME, Ranavaya M, Haig AJ, et al. A meta-analytic review of surface electromyography among persons with low back pain and normal healthy controls. J Pain. 2005;6:711-26 